\title{
Disturbance of B-vitamin status in people with type 2 diabetes in Indonesia-Link to renal status, glycemic control and vascular inflammation
}

\author{
Antonysunil Adaikalakoteswari ${ }^{a}$, Naila Rabbani ${ }^{a}$, Sarwono Waspadji ${ }^{b}$, \\ Askandar Tjokroprawiro ${ }^{c}$, Sri H.K.S. Kariadi ${ }^{d}$, John M.F. Adam ${ }^{e}$, Paul J. Thornalley ${ }^{a, *}$ \\ ${ }^{a}$ Clinical Sciences Research Laboratories, Warwick Medical School, University of Warwick, University Hospital, Coventry CV2 2DX, UK \\ ${ }^{\mathrm{b}}$ Division of Endocrinology and Metabolism, School of Medicine, University of Indonesia, Jakarta, Indonesia \\ ${ }^{\mathrm{c}}$ Division of Endocrinology and Metabolism, Department of Medicine, School of Medicine, Airlangga University and Soetomo Hospital, \\ Surabaya, Indonesia \\ d Division of Endocrinology and Metabolism, School of Medicine, Padjadjaran University, Bandung, Indonesia \\ ${ }^{\mathrm{e}}$ Division of Endocrinology, Faculty of Medicine, Hasanuddin University, Makassar, Indonesia
}

\section{A R T I C L E I N F O}

Article history:

Received 19 July 2011

Received in revised form

27 October 2011

Accepted 31 October 2011

Keywords:

Thiamine

Pyridoxine

Cobalamin

Folate

Diabetic nephropathy

Vascular inflammation

Type 2 diabetes

\begin{abstract}
A B S T R A C T
Background: Diabetes is associated with mishandling of thiamine in the kidney and development of diabetic nephropathy. The aim of this study is to assess the disturbance of thiamine and other B-vitamin status of patients with type 2 diabetes in Indonesia. Methods: One hundred and fifteen patients with type 2 diabetes with and without microalbuminuria or albuminuria and 39 healthy people were recruited. After a 2-month washout period for B-vitamin supplementation, markers of vitamins $B_{1}, B_{6}, B_{9}$ and $B_{12}$, were determined. Results: Fractional excretion of thiamine (22.8 versus $33.5 \% ; P<0.05)$ and urinary excretion of the vitamin $\mathrm{B}_{6}$ degradation product 4-pyridoxic acid ( 0.081 versus $0.133 \mu \mathrm{mol} / \mathrm{g}$ creatinine, $P<0.001)$ was increased in patients with type 2 diabetes with respect to healthy controls. There was also increased total plasma cobalamin (398 versus $547 \mathrm{pmol} / \mathrm{l}, \mathrm{P}<0.001$ ) and holotranscobalamin $(74$ versus $97 \mathrm{pmol} / \mathrm{l}, \mathrm{P}<0.001)$ in patients with type 2 diabetes. In multiple regression analysis these were linked to HbA1c, duration of diabetes and systolic blood pressure, and fasting plasma glucose, folate and C-reactive protein, respectively. Conclusions: There was renal mishandling of thiamine, increased degradation of vitamin $\mathrm{B}_{6}$ and cytosolic metabolic resistance to vitamin $\mathrm{B}_{12}$ in patients with type 2 diabetes in Indonesia.

(C) 2011 Elsevier Ireland Ltd. All rights reserved.
\end{abstract}

\footnotetext{
* Corresponding author. Tel.: +44 247696 8594; fax: +44 247696 8653/594.

E-mail address: P.J.Thornalley@warwick.ac.uk (P.J. Thornalley).

Abbreviations: ACR, albumin creatinine ratio; ALT, L-alanine:2-oxoglutarate aminotransferase; ARBs/ACEIs, angiotensin receptor blocker/angiotensin converting enzyme inhibitor; AST, aspartate aminotransferase; BMI, body mass index; CRP, C-reactive protein; CVD, cardiovascular disease; DN, diabetic nephropathy; DTT, dithiothreitol; FPG, fasting plasma glucose; $\mathrm{FE}_{\mathrm{Metabolite}}$, fractional excretion of designated metabolite; eGFR, estimated glomerular filtration rate; LC-MS/MS, liquid chromatographic with tandem mass spectrometric detection; MMA, methylmalonate; 4-PA, 4-pyridoxic acid; PL, pyridoxal; PLP, pyridoxal-5'-phosphate; PM, pyridoxamine; PMP, pyridoxamine-5'-phosphate; PN, pyridoxine; RBC, red blood cell; TFA, trifluoroacetic acid; tHcy, total plasma homocysteine ([homocysteine] $+2 \times$ [homocystine]); TK, transketolase; TMP, thiamine monophosphate; TPP, thiamine pyrophosphate; sVCAM-1, soluble vascular adhesion molecule-1.
}

0168-8227/\$ - see front matter (C) 2011 Elsevier Ireland Ltd. All rights reserved.

doi:10.1016/j.diabres.2011.10.042 


\section{Introduction}

The Southeast Asia and the Western Pacific regions are at the forefront of the current epidemic of type 2 diabetes. There is approximately 7 million people in Indonesia with diabetes, mostly type 2 diabetes, and this is predicted to rise to 12 million by 2020 [1]. There will likely be a subsequent increased burden of vascular complications of diabetes, including diabetic nephropathy (DN), in this population [2,3]. It is predicted that $25 \%$ of newly diagnosed patients with type 2 diabetes will develop early stage DN within the next 10 years [4]. The development of DN exacerbates the increased risk of cardiovascular disease (CVD) in type 2 diabetes [5]. Improvements in understanding of mechanism of development of DN and related treatment are required to decrease morbidity and premature mortality in this increasing high risk group.

Strategies to prevent DN including nutritional and therapeutic support related to B-vitamin supplements have recently emerged. Two independent intervention studies with therapeutic supplements of thiamine (vitamin $B_{1}$ ) have shown decrease in urinary albumin excretion and reversal of microalbuminuria in patients with type 2 diabetes [6,7]. This treatment may work, at least in part, by countering the effects of increased renal clearance of thiamine found in clinical diabetes [8]. Plasma levels of pyridoxal-5'-phosphate (PLP), a $B_{6}$ vitamer, were linked inversely to the vascular inflammatory marker C-reactive protein (CRP) in clinical DN [9]. Supplementation of vitamin $B_{6}$ by treatment with pyridoxine improved flow-mediated dilatation in type 1 diabetes [10]. Vitamin $B_{6}$, vitamin $B_{9}$ (folate) and vitamin $B_{12}$ (cobalamin) have been studied in relation to increased homocysteine and risk of CVD [11-13]. In studies of interactions with drug therapy, shortterm and long-term treatment with metformin has been linked to decreases in folate (5-7\%) and vitamin $\mathrm{B}_{12}(14-19 \%)$ levels in patients with type 2 diabetes receiving metformin therapy $[14,15]$. A recent finding suggested co-supplementation with $B_{6}, B_{9}$ and $B_{12}$ in patients with type 2 diabetes and advanced DN exacerbates decline in renal function [13] - an association possibly linked to adverse effects of accumulation of folate and cyanide (from cyanocobalamin treatment) in patients with impaired renal function $[16,17]$.

We hypothesised that there may be increased clearance and washout of thiamine in patients with type 2 diabetes in South East Asia and chose to study patients and people Indonesia as typical of the region. We also investigated disturbances in other B-vitamins. In this report we describe the outcome of a multicenter study of B-vitamin status of patients with type 2 diabetes with and without microalbuminuria and albuminuria and healthy people in Indonesia.

\section{Methods}

\subsection{Patients}

Patients with type 2 diabetes were recruited from those attending the diabetes clinics at CiptoMangunkusumo Hospital, Jakarta, Soetomo Hospital, Surabaya, Hasan Sadikin Hospital, Bandung and Dr Wahidin Sudirohusodo Hospital,
Makassar, Indonesia. Classification of renal function status implemented in the study is defined by the Asian-Pacific Type 2 Diabetes Policy Group and endorsed by the International Diabetes Federation [18]. Inclusion criteria were: diabetic patients - type 2 diabetes with normoalbuminuria (albumin/ creatinine ratio $A C R<22$ and $<31 \mathrm{mg} / \mathrm{g}$ for men and women, respectively), microalbuminuria (ACR $22-220$ and 31-220 mg/g for men and women, respectively) and albuminuria (ACR $>220 \mathrm{mg} / \mathrm{g}$ and plasma creatinine $<2 \mathrm{mg} / \mathrm{dl}$ ) matched for age (45-65 years) and gender - including a within group gender balance, diabetes duration $\geq 5$ years, $\mathrm{HbA}_{1 \mathrm{c}}<10 \%$ and $\mathrm{BMI} 19$ $40 \mathrm{~kg} / \mathrm{m}^{2}$ ). Urinary albumin excretion criteria were confirmed on at least 2 occasions (pre-screening and study entry). A group of healthy people of the same social background as the patients with type 2 diabetes were also recruited. Exclusion criteria were: allergy or intolerance to thiamine, pyridoxine or cobalamin, participation in another clinical study within the last 30 days, women who were pregnant, breast feeding or of child bearing potential not using adequate contraceptive precautions; for diabetic patients, chronic renal insufficiency (plasma creatinine $\geq 2 \mathrm{mg} / \mathrm{dl}$ ) [19], liver diseases (abnormal liver function tests - serum albumin, alanine transaminase, aspartate transaminase), anemia ( $\mathrm{Hb}<120 \mathrm{~g} / \mathrm{l}$ ), tuberculosis and severe CVD (angina, myocardial infarction and normal electrocardiogram within 2 months of enrolment). Medication use of the patients with type 2 diabetes was: metformin $60 \%$, $\alpha$-glycosidase inhibitor $28 \%$, sulfonylurea $54 \%$, insulin $18 \%$, angiotensin receptor blockers/angiotensin converting enzyme inhibitors (ARBs/ACEIs) 15\% and statins 15\%. Assessments for meeting the inclusion criteria were made at the initial prescreening visit to the participating clinics.

To eliminate effects of vitamin supplementation, the study involved pre-screening where meeting of inclusion and exclusion criteria was assessed followed by a washout period of 2 months for supplements with thiamine, vitamin $B_{6}$, folate and vitamin $B_{12}$. After the washout period, further peripheral venous blood (with heparin anticoagulant) and urine samples were collected after overnight fasting. Plasma and red blood cell (RBC) fractions were prepared immediately and stored at $-80^{\circ} \mathrm{C}$ until analysis. Ethical approval for the study was given by the University of Warwick Bioethics Committee, UK, and local ethical approval committees at the recruiting hospitals in Indonesia. Enrolment in the study was with informed consent. The reported investigations have been carried out in accordance with the principles of the Declaration of Helsinki as revised in 2000 .

\subsection{Biochemical measurements}

Thiamine status was assessed by measurement of thiamine, thiamine monophosphate (TMP) and thiamine pyrophosphate (TPP) in plasma, RBCs and urine, and RBC transketolase (TK) activity - all as previously described [8]. $\mathrm{B}_{6}$ vitamers (pyridoxine PN, pyridoxal PL, pyridoxal-5'-phosphate PLP, pyridoxamine PM, pyridoxamine-5'-phosphate PMP and 4-pyridoxic acid 4-PA) were determined in plasma, RBCs and urine by HPLC with post-column derivatization [20]. RBC activity of $\mathrm{L}^{-}$ alanine:2-oxoglutarate aminotransferase (ALT) and aspartate aminotransferase (AST) were determined spectrophotometrically using commercial kits (Thermo Fisher Scientific, Lough- 
borough, UK). Total plasma cobalamin and folate were determined by electrochemiluminescent immunoassay using a Roche Elecsys E170 analyzer (Roche Diagnostics UK, Burgess Hill, UK). Plasma holotranscobalamin or "active vitamin $B_{12}$ " was determined by immunoassay using an Abbott AXSYM analyser (Abbott Diagnostics, Maidenhead, UK).

Total plasma homocysteine (tHcy) and methylmalonic acid (MMA) were determined by stable isotopic dilution analysis liquid chromatography with tandem mass spectrometric detection (LC-MS/MS). Stock solutions of homocystine $(1 \mathrm{mg} / \mathrm{ml}$ in $100 \mathrm{mmol} / \mathrm{l} \mathrm{HCl}), \mathrm{MMA}(1 \mathrm{mg} / \mathrm{ml}$ in water), $\left[3,3,3^{\prime}, 3^{\prime}, 4,4,4^{\prime}, 4^{\prime}-d_{8}\right]$ homocystine $(1 \mathrm{mg} / \mathrm{ml}$ in $100 \mathrm{mmol} / \mathrm{l}$ $\mathrm{HCl})$ and [methyl- $\mathrm{d}_{3}$ ]MMA $(1 \mathrm{mg} / \mathrm{ml}$ in water; Cambridge Isotopes, Andover, MA, USA) and $500 \mathrm{~mol} / \mathrm{l}$ dithiothreitol (DTT) in water were prepared and stored in $-20^{\circ} \mathrm{C}$. The working calibration solution was prepared before analysis and further diluted to obtain calibration curve in the range 0$5 \mathrm{nmol}$ homocystine and $0-40 \mathrm{pmol} \mathrm{MMA}$ and $100 \mathrm{pmol}$ homocystine- $d_{8}$ and MMA- $d_{3}$. Isotopic standard $(10 \mu \mathrm{mol} / \mathrm{l}$ $\mathrm{d}_{8}$-homocystine and $10 \mu \mathrm{mol} / \mathrm{l} \mathrm{d}_{3}$-MMA; $10 \mu \mathrm{l}$ ) was added to plasma $(50 \mu \mathrm{l})$ and calibrators $(50 \mu \mathrm{l})$. DTT $(5 \mu \mathrm{l})$ was added and samples left at room temperature for $30 \mathrm{~min}$ on ice to reduce homocystine to homocysteine. Samples were deproteinized by ultrafiltration over $10 \mathrm{kDa}$ microspin filters $(10,000 \times \mathrm{g}$, $\left.60 \mathrm{~min}, 4^{\circ} \mathrm{C}\right)$. The ultrafiltrate $(50 \mu \mathrm{l})$ was then analysed by LCMS/MS system. The detection conditions were (molecular ion $>$ fragment ion; $m / z$ ): homocysteine, $136.1>90.1$ and $d_{4}$ Hcy, $140.1>94.1$ (collision energy $11.0 \mathrm{eV}$ and cone voltage 18.0 V, positive ion mode); MMA, $117.0>73.0$ and $d_{3}$-MMA, $120.0>76.0$ (collision energy $7 \mathrm{eV}$ and cone voltage $20 \mathrm{~V}$, negative ion mode). LC-MS/MS was performed using a Waters Acquity UPLC system with a Quattro Premier XE tandem mass spectrometric detector. For chromatographic separation, two Hypercarb columns $(5 \mu \mathrm{m}$ particle size, dimensions $50 \mathrm{~mm} \times 2.1$ and $250 \mathrm{~mm} \times 2.1 \mathrm{~mm}$ ) in series were used with a $10 \mathrm{~mm} \times 2.1 \mathrm{~mm}$ guard column (Thermo Fisher). The mobile phase components were: (A) $0.1 \%$ trifluoroacetic acid (TFA) in water and (B) $0.1 \%$ TFA in $50 \%$ acetonitrile. The elution gradient programme was: 0-10 min, 0-100\% B, 10-15 min, $100 \% \mathrm{~B}$. The flow rate was $0.2 \mathrm{ml} / \mathrm{min}$. Electrospray ionization was performed with source temperature $120^{\circ} \mathrm{C}$, desolvation gas temperature $350^{\circ} \mathrm{C}$, cone gas and desolvation gas flows 102 and $860 \mathrm{~L} / \mathrm{h}$, respectively, capillary voltage $3.0 \mathrm{kV}$ and argon collision gas $5 \times 10^{-3} \mathrm{mBar}$. Retention times, limits of quantification, inter-batch coefficients of variation and recoveries were: homocysteine $-8.8 \mathrm{~min}, 5 \mathrm{pmol}, 1.6 \%$ and 106\%; MMA $11.6 \mathrm{~min}, 2 \mathrm{pmol}, 4.3 \%$ and $105 \%$.

Clinical indicators of metabolic control were determined: fasting plasma glucose, $\mathrm{HbA}_{1 \mathrm{c}}$, plasma total cholesterol and HDL cholesterol and triglycerides. LDL cholesterol (LDL) was deduced by the Friedewald equation [21]. Nephropathy status was assessed by measurement of urinary albumin by gel permeation liquid chromatography [22]. Urinary and plasma creatinine were determined by the creatininase method. Markers of endothelial dysfunction, low grade inflammation and renal function - soluble vascular adhesion molecule-1 (sVCAM-1), CRP and cystatin c were determined by enzymelinked immunosorbent assay ( $R$ and $D$ Systems, Abingdon, UK). eGFR was deduced from plasma cystatin c concentration: $\mathrm{eGFR}=86.7 /[$ cystatin c $(\mathrm{mg} / \mathrm{l})]-4.2$ [23].

\subsection{Statistical analysis}

Data are mean \pm SD for parametric data and median (lowerupper quartile) for non-parametric data. Significance of difference between mean changes was assessed by Student's $t$ test and one-way ANOVA. Significance of difference between median changes was assessed by Mann-Whitney-U test and Kruskal-Wallis test. Bivariate correlate analysis was performed by the non-parametric Spearman method. Factors linked to markers of B-vitamin dysfunction in patients with type 2 diabetes were explored by multiple linear regression analysis. Bonferroni correction was applied to the 4 vitamin $\mathrm{B}_{6}$ vitamers (PN, PL, PLP and PMP; significance for $P<0.0125)$ and two vitamin $\mathrm{B}_{12}$ analytes (total plasma vitamin $\mathrm{B}_{12}$ and holotranscobalamin; significance for $P<0.025$ )

\section{Results}

\subsection{Characteristics of patients with type 2 diabetes and healthy people}

The characteristics of patients with type 2 diabetes and healthy people recruited for this study are given in Table 1. Study groups of patients with type 2 diabetes had a slightly higher mean age than the healthy controls. For healthy people included in the study, 2 subjects had $\mathrm{HbA}_{1 \mathrm{c}}=6.5 \%$ and were excluded from data analysis as meeting the criterion for diagnosis of diabetes by current international guidelines [24]. For the remaining healthy subjects, 22 of 37 had $\mathrm{HbA}_{1 \mathrm{c}}$ in the range $5.7-6.4 \%$, indicative of pre-diabetes by current international guidelines [24]. For patients with type 2 diabetes, 51\% had good glycemic control $\left(\mathrm{HbA}_{1 \mathrm{c}} \leq 7.0\right), 46 \%$ had moderate glycemic control $\left(\mathrm{HbA}_{1 \mathrm{c}}>7.0\right.$ and $\left.\leq 10.0\right)$ and only $3 \%$ had poor glycemic control; and $31 \%$ had hypertension. They had a slightly higher BMI than the healthy controls that was mostly due to high BMI in the albuminuria group. Overall, obesity $\left(\mathrm{BMI}>30 \mathrm{~kg} / \mathrm{m}^{2}\right)$ was low: one healthy control and $11(10 \%)$ patients with type 2 diabetes were obese. All study groups of patients with type 2 diabetes had a similar duration of diabetes. General health was assessed by blood hemoglobin, plasma albumin and plasma ALT and AST. Blood hemoglobin was $\geq 120 \mathrm{~g} / \mathrm{l}$ for all male subjects in the study. For women, 70 of the 84 females included in the study had blood hemoglobin content $\geq 120 \mathrm{~g} / \mathrm{l}, 13$ had blood hemoglobin content $\geq 110$ and $<120 \mathrm{~g} / \mathrm{l}$, and one had low blood hemoglobin content $(70 \mathrm{~g} / \mathrm{l})$ at pre-screening. Plasma ALT and AST was within the normal range in 148 and 143 subjects, respectively. The 14 patients with blood hemoglobin $<120 \mathrm{~g} / \mathrm{l}$ and 5 patients with abnormal plasma ALT and AST were retained in the analysis as other biochemical indicators were not dissimilar from patients meeting the inclusion criteria.

Markers of vascular inflammation were surprisingly littlechanged in patients with type 2 diabetes. For CRP, 7\% of healthy controls and $8 \%$ of patients with diabetes had levels higher than the upper limit of the normal range $(4.50 \mathrm{mg} / \mathrm{l})$; and for sVCAM-1, $10 \%$ of healthy controls and $11 \%$ of patients with diabetes had levels higher than the upper limit of the normal range $(0.88 \mathrm{mg} / \mathrm{l})$. There were small increases of plasma CRP in patients with diabetes and microalbuminuria 
Table 1 - Characteristics of subjects recruited for this study.

\begin{tabular}{|c|c|c|c|c|}
\hline \multirow[t]{2}{*}{ Variable } & \multirow[t]{2}{*}{ Healthy subjects } & \multicolumn{3}{|c|}{ Diabetes } \\
\hline & & Normoalbuminuria & Microalbuminuria & Albuminuria \\
\hline $\mathrm{N}$ & 37 & 53 & 36 & 26 \\
\hline Gender (M/F) & $17 / 20$ & $23 / 30$ & $16 / 20$ & $13 / 13$ \\
\hline Age (years) & $52 \pm 6$ & $57 \pm 5^{* * *}$ & $58 \pm 4^{* * *}$ & $57 \pm 6^{*}$ \\
\hline Duration of diabetes (years) & - & $8(5-14)$ & $7(5-10)$ & $8(6-10)$ \\
\hline BMI $\left(\mathrm{kg} / \mathrm{m}^{2}\right)$ & $23.6 \pm 2.9$ & $24.6 \pm 3.6$ & $24.9 \pm 3.4$ & $26.2 \pm 3.5^{* *}$ \\
\hline Plasma glucose (mM) & $4.94 \pm 0.60$ & $6.64 \pm 2.02$ & $8.31 \pm 3.06$ & $8.53 \pm 3.37^{* * *}$ \\
\hline $\mathrm{HbA}_{1 \mathrm{c}}(\%)$ & $5.73 \pm 0.42$ & $6.79 \pm 1.26^{* * *}$ & $7.36 \pm 1.21^{\ldots * *}$ & $7.70 \pm 1.15^{* * *}$ \\
\hline GFR (ml/min) & $102 \pm 29$ & $108 \pm 33$ & $96 \pm 26$ & $83 \pm 27^{*}$ \\
\hline ACR $(\mathrm{mg} / \mathrm{g})$ & $4.3(1.9-9.4)$ & $7.8(2.53-11.6)$ & $80.9(45.3-136.6)^{* \cdots,+t \dagger \dagger}$ & $891.4(486.7-2364.9)^{-\cdots+, t+t,+\neq \ddagger ~}$ \\
\hline Plasma creatinine $(\mu \mathrm{M})$ & $74 \pm 16$ & $73 \pm 20$ & $80 \pm 24$ & $93 \pm 31^{* \prime, \dagger}$ \\
\hline Systolic BP (mmHg) & $115 \pm 11$ & $123 \pm 14^{* *}$ & $131 \pm 14^{* * *, \dagger}$ & $127 \pm 16^{* *}$ \\
\hline Diastolic BP (mmHg) & $78 \pm 7$ & $79 \pm 8$ & $83 \pm 9^{*}$ & $80 \pm 9^{*}$ \\
\hline Total cholesterol (mg/dl) & $202 \pm 38$ & $197 \pm 34$ & $204 \pm 40$ & $209 \pm 50$ \\
\hline LDL (mg/dl) & $128 \pm 33$ & $119 \pm 28$ & $121 \pm 31$ & $128 \pm 42$ \\
\hline HDL (mg/dl) & $52 \pm 10$ & $52 \pm 11$ & $49 \pm 12$ & $47 \pm 9^{*}, \dagger$ \\
\hline $\mathrm{TG}(\mathrm{mg} / \mathrm{dl})$ & $103(76-138)$ & $119(82-165)$ & $148(106-204)^{* *, \dagger}$ & $147(101-175)^{*}$ \\
\hline $\mathrm{Hb}(\mathrm{g} / \mathrm{l})$ & $139 \pm 12$ & $137 \pm 13$ & $135 \pm 13$ & $139 \pm 19$ \\
\hline Albumin (g/l) & $45 \pm 2$ & $46 \pm 2$ & $46 \pm 3$ & $43 \pm 9$ \\
\hline Plasma ALT (U/ml) & $24 \pm 10$ & $24 \pm 15$ & $25 \pm 13$ & $24 \pm 16$ \\
\hline Plasma AST (U/ml) & $25 \pm 6$ & $25 \pm 10$ & $26 \pm 9$ & $25 \pm 8$ \\
\hline CRP $(\mathrm{mg} / \mathrm{l})$ & $1.01(0.49-2.20)$ & $1.08(0.38-1.95)$ & $2.15(0.64-3.05)^{*}, \dagger$ & $1.46(0.58-2.12)$ \\
\hline sVCAM-1 (mg/l) & $0.56(0.48-0.70)$ & $0.56(0.47-0.65)$ & $0.60(0.50-0.73)$ & $0.67(0.78-0.89)^{* *},+\dagger \dagger$ \\
\hline \multicolumn{5}{|c|}{$\begin{array}{l}\text { Significance: } P<0.05 \text { with respect to healthy subjects. } \\
\text { Significance: } P<0.01 \text { with respect to healthy subjects. } \\
\text { Significance: } P<0.001 \text { with respect to healthy subjects. } \\
\text { Significance: } P<0.05 \text { with respect to patients with type } 2 \text { diabetes and normoalbuminuria. } \\
\text { †† Significance: } P<0.001 \text { with respect to patients with type } 2 \text { diabetes and normoalbuminuria. }\end{array}$} \\
\hline
\end{tabular}

and slightly elevated sVCAM-1 in diabetic patients with albuminuria. Use of ARBs/ACEIs and statin therapy was relatively low - although this is still common in developing countries linked to limited access to medicines [25].

\subsection{Thiamine-related variables}

Median plasma thiamine concentration was $10.7 \mathrm{nM}$ in healthy people and was not changed significantly in patients with diabetes with or without microalbuminuria or albuminuria. Similarly RBC concentration of thiamine and activity of TK were unchanged in patients with diabetes. Urinary excretion of thiamine and $\mathrm{FE}_{\text {thiamine }}$ were increased $62 \%$ and $50 \%$, respectively, in patients with type 2 diabetes and normoalbuminuria (Table 2). Comparison of healthy subjects with all patients with diabetes combined showed that the urinary excretion thiamine was not increased in patients with type 2 diabetes whereas $\mathrm{FE}_{\text {thiamine }}$ was increased (22.8 versus $33.5 \%$; $<<0.05)$.

\subsection{Vitamin $\mathrm{B}_{6}$-related variables}

$\mathrm{B}_{6}$ vitamers, $\mathrm{PN}, \mathrm{PL}, \mathrm{PLP}$ and PMP were detected in plasma. In healthy people, PL was the quantitatively most important $B_{6}$ vitamer analyte (78\% total plasma $\mathrm{B}_{6}$ vitamers) and others minor - PLP 16\%, PN 5\% and PMP 1\%. Plasma concentrations of $\mathrm{B}_{6}$ vitamers in healthy people were (nM): PN 3.50 (2.72-5.45), PL 53.5 (45.1-67.3), PLP 10.7 (9.4-16.6) and PMP 0.89 (0.61-1.22). Plasma concentrations of PL and PLP was increased in patients with diabetes $(P<0.05$, Kruskal-Wallis); plasma PL was

\section{Table 2 - Thiamine-related variables.}

\begin{tabular}{lllll} 
Variable & Healthy subjects & \multicolumn{2}{c}{ Diabetes } \\
\cline { 3 - 5 } & & Normoalbuminuria & \multicolumn{1}{c}{ Microalbuminuria } & Albuminuria \\
\hline Plasma thiamine $(\mathrm{nM})$ & $10.7(8.5-12.9)$ & $11.5(8.4-17.6)$ & $12.3(6.7-22.3)$ & $10.0(6.1-12.3)$ \\
RBC thiamine $(\mathrm{nmol} / \mathrm{g} \mathrm{Hb})$ & $0.011(0.006-0.020)$ & $0.013(0.007-0.024)$ & $0.014(0.008-0.024)$ & $0.011(0.006-0.022)$ \\
RBC TK activity $(\mathrm{U} / \mathrm{g} \mathrm{Hb})$ & $0.34 \pm 0.11$ & $0.35 \pm 0.14$ & $0.35 \pm 0.14$ & $0.29 \pm 0.10$ \\
Urinary thiamine $(\mu \mathrm{mol} / \mathrm{g}$ creatinine) & $0.29(0.21-0.49)$ & $0.47(0.26-1.18)^{*}$ & $0.36(0.16-0.76)$ & $0.26(0.15-0.51)$ \\
FE $_{\text {thiamine }(\%)}$ & $22.8(17.0-34.7)$ & $34.2(19.9-54.7)^{*}$ & $34.0(21.1-41.9)$ & $27.8(15.6-58.3)$ \\
\hline " Significance: $P<0.05$ with respect to healthy subjects. & & &
\end{tabular}


Table 3 - Vitamin $\mathbf{B}_{6}$-related variables.

\begin{tabular}{lcccc} 
Variable & Healthy subjects & \multicolumn{2}{c}{ Diabetes } \\
\cline { 3 - 5 } & & Normoalbuminuria & Microalbuminuria & Albuminuria \\
\hline Plasma PL $(\mathrm{nM})$ & $53.5(45.1-67.3)$ & $60.3(47.5-75.0)$ & $69.4(46.4-91.5)$ & $68.4(52.8-98.6)^{*}$ \\
Plasma PLP $(\mathrm{nM})$ & $10.7(9.4-16.6)$ & $18.6(11.7-34.4)^{* *}$ & $15.5(11.7-36.7)^{*}$ & $13.1(9.4-19.8)$ \\
Plasma 4-PA $(\mathrm{nM})$ & $7.4(5.8-12.0)$ & $13.4(9.5-24.4)^{* *}$ & $12.8(10.0-23.2)^{* *}$ & $15.1(11.5-25.2)^{* * *}$ \\
Urinary PL $(\mu \mathrm{mol} / \mathrm{g}$ creatinine) & $1.00(0.77-1.14)$ & $1.11(0.92-1.28)$ & $1.08(0.98-1.41)$ & $1.20(0.97-1.57)^{* *}$ \\
Urinary 4-PA ( $\mu \mathrm{mol} / \mathrm{g}$ creatinine) & $0.081(0.063-0.098)$ & $0.142(0.097-0.201)^{* * *}$ & $0.137(0.098-0.201)^{* * *}$ & $0.106(0.084-0.183)^{* *}$ \\
(\% total B $B_{6}$ excretion) & $6.5(5.4-9.0)$ & $10.4(6.5-13.6)^{* *}$ & $9.2(6.2-13.1)^{*}$ & $6.9(4.0-9.9)$ \\
\hline
\end{tabular}

Significance: $P<0.05$ with respect to healthy subjects.

Significance: $P<0.01$ with respect to healthy subjects

Significance: $P<0.001$ with respect to healthy subjects.

increased in patients with diabetes and albuminuria and plasma PLP was increased in patients with diabetes and normoalbuminuria or microalbuminuria (Table 3).

$\mathrm{B}_{6}$ vitamers were detected in RBCs. In healthy people, $\mathrm{PL}$ and PLP were the quantitatively most important $\mathrm{B}_{6}$ vitamer analytes (31\% and 34\%, respectively, of total $\mathrm{B}_{6}$ vitamers) and other vitamers minor - PN $17 \%$ and PMP $18 \%$. $B_{6}$ vitamer concentrations in RBCs of healthy people were ( $\mathrm{nmol} / \mathrm{g} \mathrm{Hb}): \mathrm{PN}$ 0.027 (0.015-0.045), PL 0.049 (0.030-0.078), PLP 0.054 (0.039$0.070)$ and PMP $0.028(0.020-0.040)$. The levels were not changed significantly in patients with diabetes with or without microalbuminuria or macroalbuminuria. Related to this, RBC activities of PLP-dependent enzymes, ALT and AST, were $7.89 \pm 3.42$ and $27.6 \pm 9.3 \mathrm{U} / \mathrm{g} \mathrm{Hb}$ respectively, in healthy people and were also not changed in patients with diabetes (data not shown).

$\mathrm{B}_{6}$ vitamers were detected in urine of healthy people. PL was the major $B_{6}$ vitamer excreted $\left(95 \%\right.$ total $B_{6}$ vitamer excretion), with others showing only minor excretion - PN 4\%, PLP $1 \%$ and PMP $<1 \%$. Urinary excretions of $\mathrm{B}_{6}$ vitamers in healthy people were $(\mu \mathrm{mol} / \mathrm{g}$ creatinine): PN $0.040(0.029$ 0.056), PL 1.00 (0.77-1.14), PLP 0.006 (0.001-0.053), 0.0032 (0.0020-0.0048). Urinary excretion of PL was increased in patients with diabetes, with respect to healthy controls ( $P<0.05$, Kruskal-Wallis), which was attributed to increased urinary excretion of $\mathrm{PL}$ in patients with diabetes and albuminuria (Table 3). Fractional excretion of $\mathrm{B}_{6}$ vitamers in healthy people was (\%): $\mathrm{FE}_{\mathrm{PN}} 9.0$ (6.1-17.0), $\mathrm{FE}_{\mathrm{PL}} 15.4$ (13.4-16.7), $\mathrm{FE}_{\mathrm{PLP}} 0.34$ (0.07-1.85) and FE $\mathrm{FMP}_{\mathrm{PMP}} 2.7$ (1.9-5.1). Fractional excretion of $\mathrm{B}_{6}$ vitamers was not changed significantly in patients with diabetes and with or without microalbuminuria or albuminuria (data not shown).

The major degradation product of vitamin $B_{6}, 4-P A$, was detected in plasma, RBCs and urine. Plasma 4-PA was increased in patients with diabetes with or without microalbuminuria or albuminuria. RBC content of 4-PA was not changed in patients with diabetes. Urinary excretion of 4-PA was increased in all diabetic patient groups (Table 3).

\subsection{Folate, total homocysteine and vitamin $\mathrm{B}_{12}$-related variables}

The concentration of folate in plasma was not changed in patients with diabetes with or without microalbuminuria, with respect to healthy people, but was increased $14 \%$ in patients with diabetes and albuminuria. Total plasma cobalamin was increased $37 \%$ in patients with diabetes and microalbuminuria. Plasma holotranscobalamin was increased $36 \%$ and $47 \%$ in patients with diabetes and microalbuminuria and albuminuria, respectively. Plasma tHcy was increased in patients with diabetes independent of ACR status whereas MMA was not increased in patients with type 2 diabetes (Table 4). Criteria for diagnosing vitamin $B_{12}$ deficiency are plasma holotranscobalamin $<50 \mathrm{pmol} / \mathrm{l}$ and plasma MMA $>0.27 \mu \mathrm{mol} /$ 1 [26]. Applying these criteria to the study groups herein, the proportion of patients with type 2 diabetes and healthy subjects with vitamin $\mathrm{B}_{12}$ deficiency was $7 \%$ and $14 \%$, respectively.

Bivariate correlation analysis and multiple linear regression analysis for B-vitamin-related variables in patients with

\section{Table 4 - Folate, total homocysteine and vitamin $B_{12}$-related variables.}

\begin{tabular}{|c|c|c|c|c|}
\hline \multirow[t]{2}{*}{ Variable } & \multirow[t]{2}{*}{ Healthy subjects } & \multicolumn{3}{|c|}{ Diabetes } \\
\hline & & Normoalbuminuria & Microalbuminuria & Albuminuria \\
\hline Plasma folate $(\mathrm{nmol} / \mathrm{l})$ & $30.4 \pm 7.5$ & $32.7 \pm 8.4$ & $33.8 \pm 9.8$ & $34.7 \pm 10.2^{*}$ \\
\hline Total plasma cobalamin (ng/l) & $398(299-604)$ & $545(380-748)$ & $545(430-867)^{* *}$ & $568(397-682)$ \\
\hline Plasma holotranscobalamin (pmol/l) & $74(51-92)$ & $86(65-148)$ & $101(74-210)^{* *}$ & $110(91-200)^{* * *}$ \\
\hline Plasma tHcy $(\mu \mathrm{mol} / \mathrm{l})$ & $10.8(8.6-14.6)$ & $16.3(10.4-33.2)^{* *}$ & $19.2(10.0-32.1)^{* * *}$ & $18.8(12.0-28.1)^{* *}$ \\
\hline Plasma MMA ( $\mu \mathrm{mol} / \mathrm{l})$ & $0.19(0.13-0.29)$ & $0.19(0.14-0.29)$ & $0.20(0.16-0.26)$ & $0.20(0.15-0.25)$ \\
\hline
\end{tabular}


Table 5 - Multiple linear regression analysis of markers of B-vitamin disturbance in patients with type 2 diabetes.

\begin{tabular}{|c|c|c|c|c|}
\hline Dependent variable & Independent variable & $\begin{array}{l}\text { Unstandardized } \\
\text { coefficient }\end{array}$ & $\begin{array}{c}\text { Standardized } \\
\text { coefficient }\end{array}$ & $P$ \\
\hline $\mathrm{FE}_{\text {Thiamine }}(\%)$ & $\mathrm{HbA}_{1 \mathrm{c}}(\%)$ & $7.12 \pm 3.23$ & 0.21 & 0.032 \\
\hline \multirow[t]{3}{*}{ Urinary 4-PA ( $\mu \mathrm{mol} / \mathrm{g}$ creatinine) } & Duration of diabetes (years) & $0.08 \pm 0.03$ & 0.23 & 0.014 \\
\hline & Systolic blood pressure (mmHg) & $0.02 \pm 0.01$ & 0.19 & 0.045 \\
\hline & Constant & $-2.99 \pm 1.42$ & & 0.038 \\
\hline \multirow[t]{3}{*}{ Plasma holotranscobalamin (pmol/l) } & Fasting plasma glucose (mmol/l) & $16.4 \pm 3.8$ & 0.38 & $<0.001$ \\
\hline & Folate $(\mathrm{ng} / \mathrm{l})$ & $-2.55 \pm 1.09$ & -0.20 & 0.022 \\
\hline & $\mathrm{CRP}(\mathrm{mg} / \mathrm{l})$ & $9.55 \pm 4.77$ & 0.17 & 0.048 \\
\hline
\end{tabular}

Variables included in the models (excluding interrelated dependent variables in different statistical models): age, duration of diabetes, fasting plasma glucose, HbA1c, TC, LDL, HDL, TG, systolic and diastolic blood pressure, ACR, CRP, sVCAM-1, folate, GFR.

type 2 diabetes: In bivariate correlation analysis of thiamine metabolites, plasma thiamine correlated positively with urinary thiamine and RBC TK $(r=0.74, P<0.001$ and $r=0.26$, $P<0.01$, respectively). In multiple regression analysis, increased $\mathrm{FE}_{\text {thiamine }}$ was selected as the dependent variable since it is a critical marker of renal mishandling of thiamine in type 2 diabetes [8,27]. There was a positive regression of $\mathrm{FE}_{\text {thiamine }}$ on $\mathrm{HbA}_{1 \mathrm{c}}$ in patients with type 2 diabetes (Table 5).

In bivariate correlation analysis of $B_{6}$ vitamers, there were positive correlations of plasma PLP with plasma PL and 4-PA ( $r=0.44$ and 0.70, $P<0.001)$, RBC PLP, PL and 4-PA $(r=0.70,0.53$ and 0.37; $P<0.001)$ and with urinary 4-PA $(r=0.70, P<0.001)$. Plasma PL correlated positively with plasma sVCAM-1 $(r=0.29$, $\mathrm{P}<0.01)$ and urinary 4-PA correlated positively with $\mathrm{HbA}_{1 \mathrm{c}}$ (0.26, $P<0.01)$. Increased urinary excretion of 4-PA in patients of type 2 diabetes is a marker of increased degradation of vitamin $\mathrm{B}_{6}$. In multiple regression analysis, urinary excretion of 4-PA was selected as the dependent variable since it was a marker of increased vitamin $B_{6}$ degradation in type 2 diabetes. There were positive regressions of urinary excretion of 4-PA on duration of diabetes and systolic blood pressure in patients with type 2 diabetes (Table 5).

In bivariate correlation analysis of vitamin $\mathrm{B}_{12}$-related variables, plasma total vitamin $\mathrm{B}_{12}$ correlated positively with holotranscobalamin $(r=0.76, P<0.001)$, plasma glucose and $\mathrm{HbA}_{1 \mathrm{c}}(r=0.26$ and 0.25 , respectively; $P<0.01)$; and correlated negatively with plasma MMA $(r=-0.38, P<0.001)$. Plasma holotranscobalamin had similar correlates. Folate correlated positively with TG $(r=0.26, P<0.01)$. In multiple regression analysis, plasma holotranscobalamin was selected as the dependent variable since it was a marker of vitamin $B_{12}$ disturbance in type 2 diabetes. There were positive regressions of plasma holotranscobalamin on fasting plasma glucose and CRP and a negative regression with plasma folate in patients with type 2 diabetes (Table 5).

Other significant outcomes in bivariate correlation analysis were: plasma sVCAM-1 correlated positively with ACR $(r=0.40, \quad P<0.001)$ and negatively with eGFR $(r=-0.27$, $P<0.01)$; and plasma CRP correlated positively with BMI and TG $(r=0.29, P<0.01$ and $r=0.25, P<0.01$, respectively).

\subsection{Effect of drug treatment on B-vitamin status}

Patients with type 2 diabetes receiving treatment with metformin did not have any significant change in B-vitamin-related variables, compared to patients with type 2 diabetes not treated with metformin. Patients with type 2 diabetes receiving treatment with $\alpha$-glucosidase inhibitors had decreased plasma holotranscobalamin, compared to patients not treated with $\alpha$-glucosidase inhibitors: 80 (66109) versus 104 (78-209) $\mathrm{pM}, P<0.05$. They also had decreased RBC PLP concentration: 0.042 (0.031-0.064) versus 0.057 (0.040$0.088) \mathrm{pmol} / \mathrm{mg} \mathrm{Hb}(P<0.05)$. Patients with type 2 diabetes receiving treatment with sulfonylurea hypoglycaemic agents had decreased plasma holotranscobalamin, compared to patients not treated with sulfonylureas: 90 (68-113) versus 119 (78-213) pM, $P<0.05$. Patients with 2 diabetes receiving treatment with insulin did not have any significant change in $\mathrm{B}$-vitamin-related variables. Patients with 2 diabetes receiving treatment with ARBs/ACEIs had increased plasma thiamine concentration compared to patients with 2 diabetes not treated with ARBs/ACEIs: plasma thiamine concentration 15.8 (10.8-31.6) versus $10.6(6.6-16.7 \mathrm{nM}, \mathrm{P}<0.01$. Patients receiving treatment with statins had expected decreased plasma total cholesterol $(170 \pm 28$ versus $205 \pm 38 \mathrm{mg} / \mathrm{dl}$, $P<0.01)$ and LDL cholesterol $(93 \pm 26$ versus $124 \pm 29 \mathrm{mg} / \mathrm{dl}$, $P<0.001)$ but no significant difference of B-vitamin-related variables.

\section{Discussion}

Countering the effects of increased renal clearance of thiamine in clinical diabetes by thiamine supplementation is an emerging strategy to improve the treatment of earlystage DN [28]. Studies of thiamine status in healthy people have shown that urinary thiamine normalised to urinary creatinine correlates positively with $24 \mathrm{~h}$ urinary excretion of thiamine [29]. Twenty-four hour urinary excretion of thiamine also correlates with dietary intake of thiamine [30]. Urinary thiamine-creatinine ratio measured herein therefore relates to dietary intake of thiamine and was increased approximately 2 -fold in patients with type 2 diabetes and normoalbuminuria only. This was also found in previous study of patients with type 2 diabetes in the United Kingdom [8]. This may reflect improved dietary advice and compliance with it of some but not all patients with type 2 diabetes. Herein, however, patients with type 2 diabetes stratified by ACR normoalbuminuria, microalbuminuria and albuminuria - had similar duration of diabetes, $\mathrm{HbA}_{1 \mathrm{c}}$, blood pressure and lipids (except triglycerides), suggesting that patients with microalbuminuria and albuminuria had progressed to incipient and 
overt DN more rapidly than those with normoalbuminuria. Patients with microalbuminuria and albuminuria had lower urinary excretion of thiamine than those with normoalbuminuria ( 0.30 versus $0.46 \mu \mathrm{mol} / \mathrm{g}$ creatinine, $P<0.025$ ). This may reflect influence of dietary thiamine on rate of development of DN with higher dietary thiamine intake linked to slower progression of DN. This was found in the prospective Joslin Kidney Study of patients with type 1 diabetes [31].

Thiamine status showed limited disturbance in patients with type 2 diabetes, excepting 62\% increase in urinary excretion and $50 \%$ increase in $\mathrm{FE}_{\text {thiamine in patients with }}$ normoalbuminuria. The latter was also typical of all patients with diabetes combined. In healthy people the plasma concentration of thiamine was lower and $\mathrm{FE}_{\text {thiamine }}$ higher than found previously in a UK study although the urinary excretion of thiamine was similar in the two populations [8]. Plasma thiamine concentration in patients with type 2 diabetes were similar to those found in patients with type 2 diabetes in Pakistan [6]. There was also a marked lower increase in $\mathrm{FE}_{\text {thiamine }}$ in patients with type 2 diabetes than found in the UK study. The reasons for these disparities are not clear but renal handling of thiamine was nevertheless disturbed with increased washout of thiamine in patients with type 2 diabetes in Indonesia. $\mathrm{FE}_{\text {Thiamine }}$ was not correlated with urinary excretion of thiamine, suggesting that increase in $\mathrm{FE}_{\text {Thiamine }}$ was not due to increased dietary thiamine intake. Increased $\mathrm{FE}_{\mathrm{Thiamine}}$ occurs in both experimental and clinical diabetes and is linked to decreased re-uptake of thiamine from the glomerular filtrate in the renal tubules in the diabetic state $[8,27]$, likely linked to hyperglycemia-induced down regulation of thiamine transporter proteins in renal proximal tubular epithelial cells [32]. The positive regression of $\mathrm{FE}_{\text {Thiamine }}$ with $\mathrm{HbA}_{1 \mathrm{c}}$ is consistent with this mechanistic interpretation. Thiamine supplements correct associated tissue specific thiamine deficiency in diabetes (reviewed in [28]).

For vitamin $B_{6}$, there was no evidence of increased fractional excretion of $B_{6}$ vitamers in patients with type 2 diabetes, suggesting renal mishandling similar to thiamine is not present. The finding of increased plasma PLP patients with type 2 diabetes may relate to changes in tissue storage of PLP. The major pools of vitamin $B_{6}$ storage are in the skeletal muscle and liver [33]. A minor release of PLP from tissues in the diabetic state may account for this increase. The finding of increased plasma and urinary levels of 4-PA suggests there is increased degradation of $B_{6}$ vitamers in patients with type 2 diabetes. Urinary 4-PA normalised to urinary creatinine correlates positively with $24 \mathrm{~h}$ urinary excretion of 4-PA [34]. Increased urinary excretion of 4-PA in diabetes, expressed as a percentage of total vitamin $B_{6}$ excretion, was not correlated with urinary excretion of pyridoxal, suggesting that increased excretion of 4-PA is not linked to dietary intake of vitamin $\mathrm{B}_{6}$. 4-PA is formed by oxidation of PL catalysed by tissue oxidases [35]. The correlation of increased urinary excretion of 4-PA with $\mathrm{HbA}_{1 \mathrm{c}}$ suggests that increased $B_{6}$ vitamer degradation is linked to metabolic dysfunction in hyperglycemia. Multiple regression analysis revealed associations of urinary excretion of 4-PA with duration of diabetes, suggesting that degradation of vitamin $B_{6}$ may increase in severity as diabetes progresses. Increased degradation of vitamin $B_{6}$ is a novel aspect of $B$-vitamin disturbance in diabetes that may be considered in assessing requirement for vitamin supplementation.

Levels of vitamin $B_{12}$ in patients with type 2 diabetes have been studied in relation to mechanistic links to increased plasma tHcy $[12,13]$ and effects of metformin therapy $[14,15]$. Low plasma holotranscobalamin and high plasma MMA is an indicator of vitamin $B_{12}$ deficiency [26]; plasma holotranscobalamin is considered now to be a better marker of vitamin $B_{12}$ status than total plasma $B_{12}$ concentration [36]. More recently, the concept of metabolic resistance to vitamin $B_{12}$ in diabetes has been proposed to explain increased plasma levels of vitamin $B_{12}$ in the presence of markers of decreased functional activity of the vitamin - increased tHcy, for example [37]. In this study, patients with type 2 diabetes had increased total cobalamin and holotranscobalamin in plasma. There was a concomitant increase in tHcy but not of MMA. Plasma holotranscobalamin in healthy subjects and patients with type 2 diabetes and plasma MMA in all subjects groups were similar to those of a large healthy human population [38], suggesting there was likely limited voluntary supplementation of vitamin $B_{12}$ in the study groups.

Increased plasma holotranscobalamin without decrease or negative correlation with plasma tHcy but with negative correlation with MMA in patients with type 2 diabetes is a marker of vitamin $\mathrm{B}_{12}$ disturbance. Plasma holotranscobalamin in healthy subjects correlates negatively with both tHcy and MMA $[38,39]$. Increased plasma tHcy is thought to reflect decreased methyl transfer to homocysteine mediated by methylcobalamin and catalysed by methionine synthase and decreased transsulfuration to cystathionine catalysed by cystathionine- $\beta$-synthase in the cytosol of cells. Decreased methionine synthase activity and transsulfuration was found in patients with type 2 diabetes and microalbuminuria and albuminuria [40]. Formation of MMA is decreased by increased methyl transfer from methylmalonyl-CoA to form succinyl$\mathrm{COA}$ in mitochondria mediated by the mitochondrial vitamin $\mathrm{B}_{12}$ metabolite 5'-deoxyadenosyl-cobalamin. Hence, increased plasma holotranscobalamin and tHcy without increased MMA suggests there may be decreased functional activity of cobalamin, or vitamin $\mathrm{B}_{12}$ resistance, in the cytosolic but not in mitochondrial compartments of tissues in patients with type 2 diabetes - "cytosolic metabolic resistance" to vitamin $\mathrm{B}_{12}$.

Positive correlations of plasma total cobalamin and holotranscobalamin with plasma glucose and $\mathrm{HbA}_{1 \mathrm{c}}$ suggests hyperglycemia may be linked to impairment of cobalamin metabolism. Multiple regression analysis revealed a positive link of increased plasma holotranscobalamin with fasting plasma glucose and CRP, suggesting both hyperglycemia and vascular inflammation may be linked to metabolic resistance to vitamin $B_{12}$ in type 2 diabetes. Increased plasma total cobalamin and holotranscobalamin in patients with type 2 diabetes may suggest hyperglycemia impairs tissue uptake of vitamin $B_{12}$. If this is indeed so, our findings are consistent with mitochondria effectively scavenging residual vitamin $B_{12}$ taken up from the cytoplasm to maintain metabolism of MMA. These effects support and advance the concept of metabolic resistance to vitamin $\mathrm{B}_{12}$ in diabetes [37].

Vascular inflammation is thought to be a characteristic and mechanistic mediator of vascular disease in patients with type 
2 diabetes [41]. Important markers of vascular inflammation are plasma CRP and sVCAM-1. Plasma CRP has previously been linked to BMI, glucose intolerance and microalbuminuria in Western populations. In this study, plasma CRP was only increased in patients with type 2 diabetes and microalbuminuria. Nevertheless, plasma CRP correlated positively with BMI and TG. The positive link of SVCAM-1 to ACR and negative link to GFR revealed the expected links of the marker of endothelial dysfunction with decline in renal function. Plasma sVCAM-1 was increased in patients with type 2 diabetes and albuminuria compared to healthy people - as found previously [42]. In a similar study of 74 patients with diabetes in the United Kingdom, however, we found $51 \%$ of patients had sVCAM-1 levels higher than the normal range maximum whereas only $11 \%$ of patients with type 2 diabetes had sVCAM-1 levels above this level herein, which was similar percentage as in healthy controls. Good glycemic control and also genetic and dietary factors in the Indonesian study population may be linked to low vascular inflammation [41]. This study suggests that low grade inflammation is not a marked characteristic of all populations of patients with type 2 diabetes.

A 2-month washout period was included in this study between pre-screening and study entry to minimise the effects of voluntary vitamin supplementation prior to entry into the study. The half-life of thiamine in plasma is relatively short (2 days) [43] and in tissues 9-18 days [44]. For vitamin $B_{6}$ it was reasoned that concentrations of $B_{6}$ vitamers in human subjects to adjust to new amounts of dietary intake within 1020 days [33] - which has also been evidenced experimentally for plasma and RBCs pools of PLP $[45,46]$. The half-life of vitamin $B_{12}$ is ca. 400 days [47] and hence the 2-month washout period does not provide correction for tissue loading of vitamin $B_{12}$ by voluntary supplementation. The half-life of holotranscobalamin and total plasma cobalamin, however, is markedly less - ca. 3 days [48]. The washout period of 2 months provided for correction of B-vitamin levels after supplementation for thiamine, $B_{6}$ vitamers and vitamin $B_{12}$ (plasma holotranscobalamin and total cobalamin only).

A high proportion of healthy people recruited for the study, ca. $60 \%$, had $\mathrm{HbA}_{1 \mathrm{c}}$ indicative of pre-diabetes state of impaired glucose tolerance (IGT). The age range was $47-65$ years. The prevalence of IGT in Indonesia assessed by oral glucose tolerance test in 2009 for this age group was 13-18\% [49]. Analysis of B-vitamin status in healthy people with prediabetes IGT showed no significant disturbance of B-vitamin status.

There is a possibility that patients with type 2 diabetes in this study with microalbuminuria and albuminuria developed nephropathy independent of the presence of diabetes. The criteria for patients with type 2 diabetes and microalbuminuria or albuminuria were a documented diagnosis of type 2 diabetes mellitus of $\geq 5$ years and presence of microalbuminuria or albuminuria on 2 or more occasions - including at prescreening and study entry. The Collaborative Study Group, using entry criteria similar to these found that $94 \%$ of patients with type 2 diabetes and nephropathy had diabetic glomerulosclerosis on biopsy [50]. The presence of non-diabetic nephropathy was, therefore, likely limited and the outcomes of study groups type 2 diabetes with and microalbuminuria or albuminuria are indeed attributable to diabetic incipient and overt nephropathy, respectively.

Assessing the effects of medication of patients with type 2 diabetes on B-vitamin status, there was no disturbance of Bvitamin status with treatment by metformin, insulin nor statins. Treatment with $\alpha$-glucosidase inhibitors and sulfonylureas was, however, linked to decreased plasma holotranscobalamin, and treatment with $\alpha$-glucosidase inhibitors also linked to decreased RBC concentration of PLP. Treatment with ARBs/ACEIs was associated with increased plasma thiamine concentration, suggesting that benefits of these agents may also be associated with decreasing renal clearance of thiamine. The number of patients in this study receiving treatment with ARBs/ACEIs was small, however, and this effect requires confirmation in a larger patient group.

The clinical significance of B-vitamin disturbance in patients with type 2 diabetes found herein may be judged from vitamin supplementation studies. Supplementation with thiamine of patients with type 2 diabetes reversed early-stage kidney disease - a response that may be linked to correcting renal deficiency of thiamine linked to this increased thiamine washout [28]. Previous studies of supplementation with vitamins $B_{6}, B_{9}$ and $B_{12}$ in patients with vascular disease or diabetes found no effect of co-supplementation on death from CVD, decreased risk of stroke and increased risk of unstable angina (HOPE-2) study [12] and patients with type 1 or type 2 diabetes mellitus and advanced $\mathrm{DN}$ increased the rate of decline in renal function (DIVINe study) [13]. Folate and cyanide from cyanocobalamin treatment are possible factors linked to adverse effects in the DIVINe study [16,17], which may negate otherwise beneficial effects of vitamin $B_{6}$ and $B_{12}$ supplementation, but this requires further investigation. Currently countering the effects of diabetes-induced renal washout of thiamine by thiamine supplementation appears to be the most important disturbance of B-vitamin metabolism requiring correction for improved clinical outcome.

\section{Conclusions}

This study shows that there was increased $\mathrm{FE}_{\text {thiamine }}$ in patients with type 2 diabetes - suggesting renal mishandling of thiamine, increased urinary excretion of 4-PA - indicative of increased vitamin $B_{6}$ degradation, and increased tHcy without increased MMA in the presence of increased plasma total and active vitamin $B_{12}$, consistent with cytosolic metabolic resistance to vitamin $B_{12}$. There were also modest increases of plasma CRP and SVCAM-1 in patients with type 2 diabetes with microalbuminuria and albuminuria, respectively, suggesting limited vascular inflammation. Therefore, in Indonesia patients with type 2 diabetes - typical of the South East Asian region, there is increased washout of thiamine, degradation of vitamin $\mathrm{B}_{6}$ and cytosolic metabolic resistance to vitamin $\mathrm{B}_{12}$ without marked vascular inflammation.

\section{Conflict of interest}

The authors have a competing interest to declare. P.J.T. received honoraria from MercK KGaA (Germany) for speaking 
at expert meetings on "The Role of B-vitamins in Preventing Diabetic Complications" in 2010 and 2011.

\section{Acknowledgements}

This study was funded by Merck KGaA (Darmstadt, Germany). The funder had no influence on data analysis or interpretation. We thank: contract research organisations Prodia and Equilab (Jakarta, Indonesia) for storage and conveyance of clinical samples from the clinical centres in Indonesia to the University of Warwick, U.K.; Clinical Biochemistry, University Hospital of Coventry and Warwickshire, Coventry, UK (Head: Dr Steve Smith) for analysis of plasma and urinary creatinine, total and active plasma cobalamin, plasma folate and $\mathrm{HbA}_{1 \mathrm{c}}$; Neil T. Raymond, Associate Professor in Epidemiology, University of Warwick, for review of the study design; and Drs Ulrike Hostalek and Dieter Bonke (Merck KGaA) for critical reading of the manuscript.

\section{R E F E R E N C E S}

[1] Shaw JE, Sicree RA, Zimmet PZ. Global estimates of the prevalence of diabetes for 2010 and 2030. Diabetes Res Clin Pract 2010;87:4-14.

[2] Parving HH, Lewis JB, Ravid M, Remuzzi G, Hunsicker LG. Prevalence and risk factors for microalbuminuria in a referred cohort of type II diabetic patients: a global perspective. Kidney Int 2006;69:2057-63.

[3] Wu AYT, Kong NCT, de Leon FA, Pan CY, Tai TY, Yeung VTF, et al. An alarmingly high prevalence of diabetic nephropathy in Asian type 2 diabetic patients: the MicroAlbuminuria Prevalence (MAP) Study. Diabetologia 2005;48:17-26

[4] Nielsen SE, Sugaya T, Hovind P, Baba T, Parving HH, Rossing P. Urinary liver-type fatty acid-binding protein predicts progression to nephropathy in type 1 diabetic patients. Diabetes Care 2010;33:1320-4.

[5] de Zeeuw D, Remuzzi G, Parving HH, Keane WF, Zhang Z, Shahinfar S, et al. Albuminuria, a therapeutic target for cardiovascular protection in type 2 diabetic patients with nephropathy. Circulation 2004;110:921-7.

[6] Rabbani N, Shahzad Alam S, Riaz S, Larkin JR, Akhtar MW, Shafi T, et al. High dose thiamine therapy for patients with type 2 diabetes and microalbuminuria: a pilot randomised, double-blind, placebo-controlled study. Diabetologia 2009;52:208-12.

[7] Sihag B, Meena B, Agrawal R, Meel J, Sirohi P, Bishnoi P. High dose thiamine therapy for patients with type 2 diabetes and microalbuminuria: a randomised, doubleblind placebo-controlled study. Diabetes Obes Metab 2010;12:87-8.

[8] Thornalley PJ, Babaei-Jadidi R, Al Ali H, Rabbani N, AntonySunil A, Ahmed A, et al. High prevalence of low plasma thiamine concentration in diabetes linked to marker of vascular disease. Diabetologia 2007;50:2164-70.

[9] Friedman AN, Hunsicker LG, Selhub J, Bostom AG. Clinical and nutritional correlates of C-reactive protein in type 2 diabetic nephropathy. Atherosclerosis 2004;172:121-5.

[10] MacKenzie KE, Wiltshire EJ, Gent R, Hirte C, Piotto L, Couper JJ. Folate and vitamin B-6 rapidly normalize endothelial dysfunction in children with type 1 diabetes mellitus. Pediatrics 2006;118:242-53.
[11] Herrmann W, Schorr H, Obeid R, Makowski J, Fowler B, Kuhlmann MK. Disturbed homocysteine and methionine cycle intermediates S-adenosylhomocysteine and Sadenosylmethionine are related to degree of renal insufficiency in type 2 diabetes. Clin Chem 2005;51:891-7.

[12] Lonn E, Yusuf S, Arnold MJ, Sheridan P, Pogue J, Micks M, et al. Homocysteine lowering with folic acid and B vitamins in vascular disease. New Engl J Med 2006;354:1567-77.

[13] House AA, Eliasziw M, Cattran DC, Churchill DN, Oliver MJ, Fine A, et al. Effect of B-vitamin therapy on progression of diabetic nephropathy a randomized controlled trial. JAMA 2010;303:1603-9.

[14] Wulffele MG, Kooy A, Lehert P, Bets D, Ogterop JC, Burg B, et al. Effects of short-term treatment with metformin on serum concentrations of homocysteine, folate and vitamin B12 in type 2 diabetes mellitus: a randomized, placebocontrolled trial. J Intern Med 2003;254:455-63.

[15] de Jager J, Kooy A, Lehert P, Wulffele MG, van der Kolk J, Bets $\mathrm{D}$, et al. Long term treatment with metformin in patients with type 2 diabetes and risk of vitamin B-12 deficiency: randomised placebo controlled trial. Br Med J 2010;340.

[16] Thornalley PJ, Rabbani N, Therapy. Vitamin B6, B9 and B12 in diabetic nephropathy-beware. Nat Rev Endocrinol 2010;6:477-8.

[17] Koyama K, Yoshida A, Takeda A, Morozumi K, Fujinami T, Tanaka N. Abnormal cyanide metabolism in uraemic patients. Nephrol Dial Transplant 1997;12:1622-8.

[18] Asian-Pacific Type 2 Diabetes Policy Group and International Diabetes Federation. Type 2 diabetes. Practical targets and treatments, 4th ed., International Diabetes Institute; 2005. pp. 1-62.

[19] Maschio G, Oldrizzi L, Rugiu C. Is there a point-of-no-return in progressive renal-disease. J Am Soc Nephrol 1991;2:83240.

[20] Bisp MR, Bor MV, Heinsvig EM, Kall MA, Nexo E. Determination of vitamin B6 vitamers and pyridoxic acid in plasma: development and evaluation of a highperformance liquid chromatographic assay. Anal Biochem 2002;305:82-9.

[21] Friedewald WT, Levy RI, Fredrickson DS. Estimation of the concentration of low-density lipoprotein cholesterol in plasma, without use of the preparative ultracentrifuge. Clin Chem 1972;18:499-502.

[22] Comper WD, Osicka TM, Clark M, MacIsaac RJ, Jerums G. Earlier detection of micro albuminuria in diabetic patients using a new urinary albumin assay. Kidney Int 2004;65:1850-5.

[23] Chudleigh R, Ollerton R, Dunseath G, Peter R, Harvey J, Luzio S, et al. Use of cystatin C-based estimations of glomerular filtration rate in patients with type 2 diabetes. Diabetologia 2009;52:1274-8.

[24] American Diabetes Association. Standards of Medical Care in Diabetes-2010. Diabetes Care 2010;33:S11-61.

[25] Joshi R, Jan S, Wu Y, MacMahon S. Global inequalities in access to cardiovascular health care: our greatest challenge. J Am Coll Cardiol 2008;52:1817-25.

[26] Herrmann W, Obeid R, Causes. Early diagnosis of vitamin B(12) deficiency. Dtsch Arztebl Int 2008;105:680-5.

[27] Babaei-Jadidi R, Karachalias N, Ahmed N, Battah S, Thornalley PJ. Prevention of incipient diabetic nephropathy by high dose thiamine and benfotiamine. Diabetes 2003;52:2110-20.

[28] Rabbani N, Thornalley PJ. Emerging role of thiamine therapy for prevention and treatment of early-stage diabetic nephropathy. Diabetes Obes Metab 2011;13:577-83.

[29] Ihara H, Matsumoto T, Kakinoki T, Shino Y, Hashimoto R, Hashizume N. Estimation of vitamin B1 excretion in 24-hr 
urine by assay of first-morning urine. J Clin Lab Anal 2008;22:291-4.

[30] Tasevska N, Runswick SA, McTaggart A, Bingham SA. Twenty-four-hour urinary thiamine as a biomarker for the assessment of thiamine intake. Eur J Clin Nutr 2007;62:1139-47.

[31] AntonySunil A, Perkins B, Krolewski A, Rabbani N, Thornalley PJ. Thiamine status and risk of early renal function decline in type 1 diabetic patients. Diabetologia 2008;51:S98

[32] Larkin JR, Rabbani N, Zehnder D, Thornalley PJ. Down regulation of thiamine transporter expression in human tubular epithelial cells in vitro and increased thiamine clearance in diabetes. Diabetes 2011;60:A1.

[33] Coburn SP. Location and turnover of vitamin B6 pools and vitamin B6 requirements of Humansa. Ann N Y Acad Sci 1990;585:76-85.

[34] Schuster K, Bailey LB, Cerda JJ, Gregory JF. Urinary 4pyridoxic acid excretion in 24-hour versus random urine samples as a measurement of vitamin B6 status in humans. Am J Clin Nutr 1984;39:466-70.

[35] Merrill AH, Henderson JM, Wang E, McDonald BW, Millikan WJ. Metabolism of vitamin B-6 by human liver. J Nutr 1984;114:1664-74.

[36] Nexo E, Hoffmann-Lucke E. Holotranscobalamin, a marker of vitamin B-12 status: analytical aspects and clinical utility. Am J Clin Nutr 2011;94:359S-65S.

[37] Solomon LR. Diabetes as a cause of clinically significant functional cobalamin deficiency. Diabetes Care 2011;34:1077-80.

[38] Vogiatzoglou A, Oulhaj A, Smith AD, Nurk E, Drevon CA, Ueland PM, et al. Determinants of plasma methylmalonic acid in a large population: implications for assessment of vitamin B12 status. Clin Chem 2009;55: 2198-206.

[39] Refsum H, Johnston C, Guttormsen AB, Nexo E. Holotranscobalamin and total transcobalamin in human plasma: determination, determinants, and reference values in healthy adults. Clin Chem 2006;52:129-37.

[40] Tessari P, Coracina A, Kiwanuka E, Vedovato M, Vettore M, Valerio A, et al. Effects of insulin on methionine and homocysteine kinetics in type 2 diabetes with nephropathy. Diabetes 2005;54:2968-76.

[41] Kolb H, Mandrup-Poulsen T. The global diabetes epidemic as a consequence of lifestyle-induced low-grade inflammation. Diabetologia 2010;53:10-20.

[42] Koga M, Otsuki M, Kubo M, Hashimoto J, Kasayama S. Relationship between circulating vascular cell adhesion molecule- 1 and microvascular complications in Type 2 diabetes mellitus. Diabet Med 1998;15:661-7.

[43] Weber W, Kewitz H. Determination of thiamine in human plasma and its pharmacokinetics. Eur J Clin Pharmacol 1985;28:213-9.

[44] Ariaey-Nejad MR, Balaghi M, Baker EM, Sauberlich HE. Thiamin metabolism in man. Am J Clin Nutr 1970;23:764-78.

[45] Cuskelly GJ, Stacpoole PW, Williamson J, Baumgartner TG, Gregory JF. Deficiencies of folate and vitamin B6 exert distinct effects on homocysteine, serine, and methionine kinetics. Am J Physiol Endocrinol Metab 2001;281: E1182-E1190.

[46] Lamers Y, O'Rourke B, Gilbert LR, Keeling C, Matthews DE, Stacpoole PW, et al. Vitamin B-6 restriction tends to reduce the red blood cell glutathione synthesis rate without affecting red blood cell or plasma glutathione concentrations in healthy men and women. Am J Clin Nutr 2009;90:336-43.

[47] Heyssel RM, Bozan RC, Darby WJ, Bell MC. Vitamin B12 turnover in man: the assimilation of vitamin B12 from natural foodstuff by man and estimates of minimal daily dietary requirements. Am J Clin Nutr 1966;18:176-84.

[48] Nexo E, Hvas AM, Bleie O, Refsum H, Fedosov SN, Vollset $\mathrm{SE}$, et al. Holo-transcobalamin is an early marker of changes in cobalamin homeostasis. A randomized placebocontrolled study. Clin Chem 2002;48:1768-71.

[49] Mihardja L, Delima, Siswayo H, Ghani L, Soegondo S. Prevalence and determinants of diabetes mellitus and impaired glucose tolerance in Indonesia. Acta Med Indones 2009;41:169-74.

[50] Schwartz MM, Lewis EJ, Leonard-Martin T, Lewis JB, Batlle D. Renal pathology patterns in type II diabetes mellitus: relationship with retinopathy. The Collaborative Study Group. Nephrol Dial Transplant 1998;13:2547-52. 